\title{
Conformational and Topology Analysis of Diphenylthiourea and Diarylhalidethiourea Compounds Using DFT
}

\author{
Nur Najwa-Alyani Mohd Nabil ${ }^{1}$ and Lee Sin Ang, ${ }^{2 * *}$ \\ ${ }^{1}$ Fakulti Sains Gunaan, Universiti Teknologi MARA, 40450 Shah Alam, Selangor Darul Ehsan, Malaysia \\ ${ }^{2}$ Fakulti Sains Gunaan, Universiti Teknologi MARA, Cawangan Perlis, Kampus Arau, \\ 02600 Arau, Perlis Indera Kayangan, Malaysia
}

* Corresponding author:

email:anglee631@perlis.uitm.edu.my

Received: November 9, 2018

Accepted: January 11, 2019

DOI: $10.22146 /$ ijc. 40663

\begin{abstract}
The disubstituted thiourea compounds have shown its reliability on their usages in various industries compared to the thiourea compounds. However, they also show capability to exist in different configurations, which would render them to possess different properties and hence affect their usability by unsuspected users. In this study, investigation was carried out on the polymorphism of five disubstituted thiourea compounds in which the phenyl rings and arylhalide acted as substituents. Using the B3LYP/DEF2-TZVP model chemistry with D3-BJ and gCP correctional schemes, the energetic analysis on the possible structural arrangements of the compounds was performed. The topology analysis of non-covalent interaction and electrostatic potential surfaces was used for understanding the interaction and reactivity of the constitute molecules of the compounds. Energetic results show that for all interested compounds, CT and TT configurations may coexist. Between the two types of substituents, phenyl substituted molecules are more flexible with better capability to be nucleophilic compounds. On the other hand, the arylhalide substituted molecules form better electrophilic compounds. The reactive sites of the molecules rotated to the stable new configurations are similar to the molecules in their original configurations observed from experiments.
\end{abstract}

Keywords: conformational analysis; topology analysis; thiourea substituent compounds; density functional theory

\section{- INTRODUCTION}

Thiourea molecules have three potential coordination sites: the sulphur of thiourea moiety $\left(\mathrm{S}_{\mathrm{T}}\right)$ and the two nitrogen atoms of the NH group. One of the thiourea derivatives, the symmetrically disubstituted thioureas, which have the form RHN-(C=S)-NHR' where $R=R$, have received much interest due to their diverse applications in medicine, agriculture, and chemical industries [1-5]. In addition, disubstituted thioureas are known to form stable, neutral coordination compounds with various transition metal ions [6].

This study focusses on five disubstituted thiourea compounds, as listed in Table 1. Two types of substituents were considered, namely phenyl rings and arylhalides. The phenyl substituted $(\mathrm{Ph})$ compounds are labelled as
$\mathrm{Ph}-1,2,3$ and 4 to indicate compounds from different works. For arylhalide substituted (Ah) compounds, $\mathrm{Ph}$ $\mathrm{F}, \mathrm{Ph}-\mathrm{Cl}$ and $\mathrm{Ph}-\mathrm{Br}$ were considered, indicating attachment of fluorine, chlorine and bromine atoms to the phenyl ring. The attachment of the halogens at the ortho- and the para- site to the phenyl ring (as shown in Fig. 1) is appended with $\mathrm{o}^{-}$and $\mathrm{p}-$, respectively. Experimentally, for these compounds, the structural arrangements of the molecules are shown to have preference towards the trans-trans (TT) and cis-trans (CT) configurations. As shown in Table 1, there is no connection between the crystal system and occurrence of TT or CT configurations. Thus, all these compounds show unrelated relationship of the configuration, crystal system and type of substituent. It has to be mentioned that 
Table 1. List of the phenyl and arylhalide substituted compounds considered in this study

\begin{tabular}{|c|c|c|c|c|}
\hline No. & Compound & $\begin{array}{l}\text { Original configuration } \\
\text { of the molecules }\end{array}$ & Crystal system & Substituent \\
\hline \multirow{4}{*}{1} & \multirow{4}{*}{ 1,3-diphenylthiourea $\left(\mathrm{C}_{13} \mathrm{H}_{12} \mathrm{~N}_{2} \mathrm{~S}_{1}\right)[7-8]\left(^{\star}\right)$} & TT & orthorhombic & $\mathrm{Ph}-1$ \\
\hline & & СТ & monoclinic & $\mathrm{Ph}-2$ \\
\hline & & TT & orthorhombic & $\mathrm{Ph}-3$ \\
\hline & & TT & orthorhombic & $\mathrm{Ph}-4$ \\
\hline 2 & 1,3-bis(4-fluorophenyl)thiourea $\left(\mathrm{C}_{13} \mathrm{H}_{10} \mathrm{~F}_{2} \mathrm{~N}_{2} \mathrm{~S}_{1}\right)[9]$ & TT & orthorhombic & $\mathrm{Ph}-\mathrm{F}-\mathrm{p}$ \\
\hline \multirow[b]{2}{*}{3} & \multirow{2}{*}{ 1,3-bis(4-chlorophenyl)thiourea $\left(\mathrm{C}_{13} \mathrm{H}_{10} \mathrm{~N}_{2} \mathrm{~S}_{1}\right)$ [10-11] } & TT & orthorhombic & $\mathrm{Ph}-\mathrm{Cl}-\mathrm{p}-1$ \\
\hline & & TT & monoclinic & $\mathrm{Ph}-\mathrm{Cl}-\mathrm{p}-2$ \\
\hline 4 & 1,3-bis(4-bromophenyl)thiourea $\left(\mathrm{C}_{13} \mathrm{H}_{10} \mathrm{Br}_{2} \mathrm{~N}_{2} \mathrm{~S}_{1}\right)$ [12] & TT & monoclinic & $\mathrm{Ph}-\mathrm{Br}-\mathrm{p}$ \\
\hline \multirow{2}{*}{5} & \multirow{2}{*}{ 1,3-bis(2-chlorophenyl)thiourea $\left(\mathrm{C}_{13} \mathrm{H}_{10} \mathrm{Cl}_{2} \mathrm{~N}_{2} \mathrm{~S}_{1}\right)$ [13-14] } & CT & orthorhombic & $\mathrm{Ph}-\mathrm{Cl}-\mathrm{O}-1$ \\
\hline & & TT & monoclinic & $\mathrm{Ph}-\mathrm{Cl}-\mathrm{O}-2$ \\
\hline
\end{tabular}

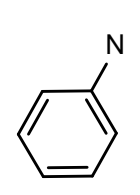

$\mathrm{Ph}$

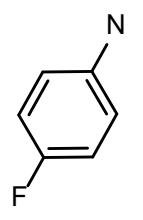

$\mathrm{Ph}-\mathrm{F}-\mathrm{p}$

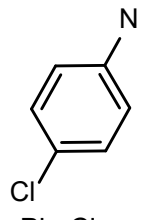

$\mathrm{Ph}-\mathrm{Cl}-\mathrm{p}$

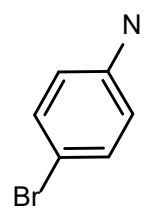

$\mathrm{Ph}-\mathrm{Br}-\mathrm{p}$

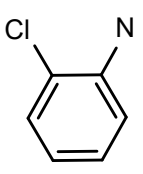

$\mathrm{Ph}-\mathrm{Cl}-\mathrm{O}$

Fig 1. The molecular structure of the arylhalide substituent compounds

cis-cis (CC) configuration is conspicuously missing in Table 1 as it is not found to be favorable for these thiourea derivatives.

The existence of the same compounds with different stable configurations (CT and TT, shown in Table 1) as found from the experiments rendered the compounds conformationally polymorphic. In general, polymorphic compounds with different structural arrangements, would lead to different properties of the compounds due to the different intra- and intermolecular interaction. For the compounds considered in this study, those in TT configuration always have the molecules stack in head-totail to form zigzag tapes. It involves twin $\mathrm{NH} \cdots \mathrm{S}_{\mathrm{T}}$ contacts of 2.50 to $2.70 \mathrm{Bohr}[7-12,14]$. The $\mathrm{NH} \cdots \mathrm{S}_{\mathrm{T}}$ contact can be interpreted as hydrogen-bonding interactions to a bifurcated sulphur acceptor. It is similar in the TT configuration of the arylhalide compounds as the $\mathrm{NH}^{\cdots} \mathrm{S}_{\mathrm{T}}$ hydrogen bonds are known as a characteristic part of the solid-state assembly of thiourea molecules [15]. The headto-tail orientation is common for TT configuration as dimer aromatic rings are favored to be in T-shaped $\left(90^{\circ}\right.$ angle between dimer) or slipped parallel [16]. However, for CT configuration compounds, centrosymmetric orientation is shown with one $\mathrm{NH} \cdots \mathrm{S}_{\mathrm{T}}$ interaction with opposite substituents away from the thiourea moiety.

This work is carried out to study the polymorphic phenomenon of the $\mathrm{Ph}$ - and Ah-substituted thiourea compounds. It is aimed to find the effect of different configurations to the properties of the molecules without changing the intermolecular hydrogen bonding and geometry of the molecules. Changing the entire geometry of the molecule to the minimum forces would exchange the real crystal structure of the molecules and lose the effect of the configuration changes. The addition of the halogens to the phenyl ring at different sites may alter the intra- and intermolecular interactions significantly, resulting in configurations that are stable but yet-to-befound from experiments. Furthermore, the electronic properties of the compounds in the gaseous state of monomer and dimer systems would also be investigated, as to provide insights to alterations in the properties between the original and predicted configurations. 


\section{- COMPUTATIONAL METHODS}

The geometries of interested compounds, taken from Cambridge Structural Database (CSD), were all fixed with rotation only along the $\mathrm{C}-\mathrm{N}$ bond between the thiourea moiety and its substituents. Avoiding the geometry changes will preserve the interaction for the parts not affected by the rotation (as obtained from experimental studies). The cis- (C) and trans- (T) orientations referred in the following sections are based on the relative orientation of the hydrogen to the sulphur in each conformer as depicted in Fig. 2. For the calculations of the dimer systems, the same sides of each molecule were rotated simultaneously.

The calculations were carried out using the Gaussian 09 suite of programs [17]. Previous electronic properties study on the other thiourea derivative molecules was proved reliable using B3LYP [18]. Thus, the single point calculations were performed at B3LYP level of theory with the DEF2-TZVP as the basis set. Previous study had suggested that DEF2-TZVP offers a good balance between accuracy and performance for molecules [19-20]. At DFT level, DEF2-TZVP basis is proved to be able to achieve results that are almost similar to the DEF2-QZVP [21]. It is also performed well when combined with DFT method [22-23]. However, due to the lack in describing the dispersion, D3-BJ [24] correctional scheme is included in this study. To verify the stability of the method, calculations were performed on the S66 dataset using Cuby4 [25] interfaced with Gaussian 09 [17]. The RMSE obtained is $0.71 \mathrm{kcal} / \mathrm{mol}$. Comparing to the previous study reported by Jan Rezac [26], other methods, i.e. methods MP2/TZ and CCSD/CBS also have similar RMSE energy. Thus, method used in this study is sufficient to be used for the interested compound. For dimers, gCP scheme is included to reduce the basis set superposition error [27]. The total energy is then given as:

$\mathrm{E}_{\mathrm{T}}=\mathrm{E}_{\mathrm{SCF}}+\mathrm{E}_{\mathrm{D} 3-\mathrm{BJ}}+\mathrm{E}_{\mathrm{gCP}}$

where $\mathrm{E}_{\mathrm{T}}$ is the total energy of the cluster, which is the sum of self-consistent field energy $\mathrm{E}_{\mathrm{SCF}}$, corrective energies of dispersion $\mathrm{E}_{\mathrm{D} 3 \text {-BJ }}$ and counterpoise correction of gCP, $\mathrm{E}_{\mathrm{gCP}}$. The relative energy is then used to compare the stability between two different configurations.

Another energy analysis used to study the stability of compounds is by using the interaction energy of the dimers. Interaction energy is caused by interaction of both monomers to form the compound [28]. The positive energy shows the repulsive interaction while the negative shows the attractive interactions.

Topology analysis were performed to complement the energetic results. The non-covalent interaction (NCI) using the reduced density gradient (RDG) was performed using the Multiwfn software [29]. The results are shown through the visual molecular dynamics program (VMD) [30]. The 3D NCI isosurface of a compound is colored according to the corresponding values of $\operatorname{sign}\left(\lambda_{2}\right) \rho$ (shown in Fig. 3). It is an indicator of the types of interactions. For this study, the Blue-GreenRed (BGR) scheme was used where blue indicates bonding interaction, green is of $\mathrm{vdW}$ and red indicates non-bonding interactions. $0.3 \mathrm{au}$ isosurface cutoff and color scale of $-0.04<\rho<0.02$ were used for this study. These quantities were proved to encapsulate the noncovalent interaction region of interest [31].

The further studies on the reactivity of the compounds were performed using the electrostatic potential (ESP) surfaces. For this study, the color range of red-green-blue (RGB) was used. Red and blue indicate
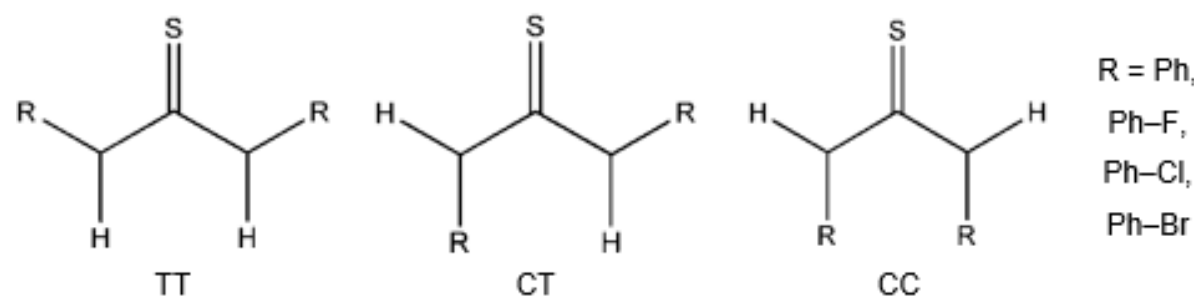

Fig 2. The conformers of the diphenylthiourea and arylhalide thiourea compounds 


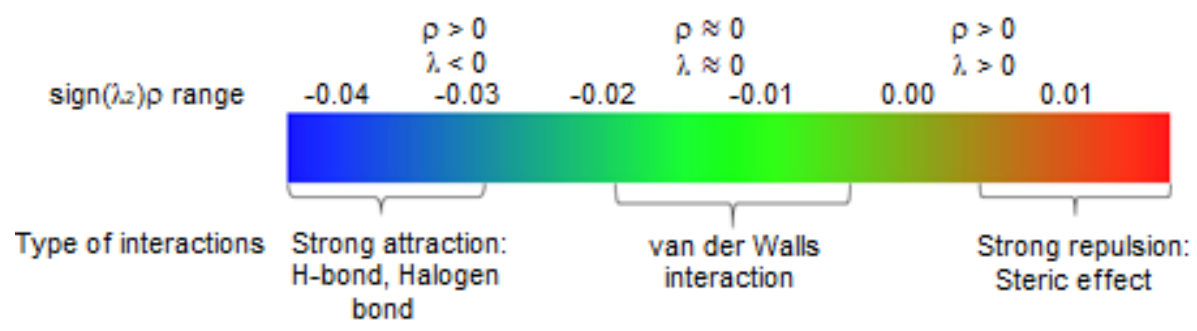

Fig 3. The range of color for the NCI isosurfaces

electron abundance (most negative sites) and depletion (most positive sites) respectively while green color indicates uniform electron distribution. Preferable isosurface of $0.001 \mathrm{au}$ is used in this study as it shows the surface lies beyond the van der Waals radii [32]. The ESP surfaces was post-processed using the Gauss View program [33].

\section{- RESULTS AND DISCUSSION}

\section{Stability Analysis}

For the energetic analysis, as tabulated in Table 2, it can be seen that CT configuration is the most preferable configuration, followed by TT configuration. Both of these configurations are the low-energy conformation with relative energy range from 0.1 to $0.2 \mathrm{eV}$. The $\mathrm{CC}$ configuration is the least preferable configuration with high relative energy (between 3.4 to $7.2 \mathrm{eV}$ ). This observation can be related to the results from the experiments where only polymorphs in TT and CT configurations were obtained. CT configuration is preferable as it had delocalization between the substituent with the thiourea moiety. The TT configuration are less preferable from the steric repulsive of the nitrogen lone pair and CC configuration had steric repulsion of the substituents [2,34]. Results also show that comparing between $\mathrm{Ph}$ - and $\mathrm{Ah}$ substituents, $\mathrm{Ph}$-substituent is more flexible to be in $\mathrm{CT}$, TT and CC configuration while CC only exists for PhCl-p-1 of Ah-substituent.

Even though both the CT and TT configurations are shown to be possible in the monomer systems, rotation of the dimer systems shows that the substituents are too close or overlapping (as shown in Fig. 4 for the dimer of $\mathrm{Ph}-\mathrm{Cl}-\mathrm{p}$ ). Thus, those dimers are unable to exist with new configuration in a similar crystal system. However, the possibility for them to exist in different configuration of different crystal systems cannot be discarded.

Table 2. Summaries of the possible configuration for monomer of the $\mathrm{Ph}$ - and $\mathrm{Ah}$-substituted molecules. For each set, the minimum energy conformation is used as the reference

\begin{tabular}{lccccc}
\hline \multirow{2}{*}{ Substituent } & $\begin{array}{l}\text { Most Stable } \\
\text { Configuration }\end{array}$ & \multicolumn{5}{c}{$\begin{array}{c}\text { Other possible configuration with its relative } \\
\text { energy (eV) }\end{array}$} \\
\hline $\mathrm{Ph}-1$ & CT & TT & 0.1377 & CC & 6.6177 \\
$\mathrm{Ph}-2$ & CT & TT & 0.2045 & & \\
$\mathrm{Ph}-3$ & CT & TT & 0.1761 & CC & 6.5187 \\
$\mathrm{Ph}-4$ & CT & TT & 0.1731 & CC & 7.2727 \\
$\mathrm{Ph}-\mathrm{F}$ & CT & TT & 0.1569 & CC & 3.3776 \\
$\mathrm{Ph}-\mathrm{Cl}-\mathrm{p}-1$ & CT & TT & 0.1537 & CC & 6.4029 \\
$\mathrm{Ph}-\mathrm{Cl}-\mathrm{p}-2$ & CT & TT & 0.1031 & & \\
$\mathrm{Ph}-\mathrm{Br}$ & CT & TT & 0.1464 & & \\
$\mathrm{Ph}-\mathrm{Cl}-\mathrm{o}-1$ (a) & CT & TT & 0.1237 & & \\
$\mathrm{Ph}-\mathrm{Cl}-\mathrm{o}-1$ (b) & CT & TT & 0.1860 & & \\
$\mathrm{Ph}-\mathrm{Cl}-\mathrm{o}-2$ & CT & TT & 0.1779 & & \\
\hline
\end{tabular}




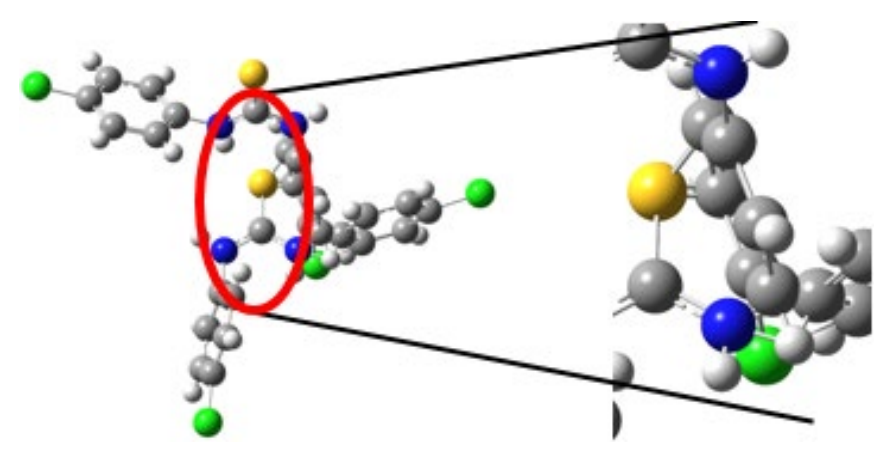

Fig 4. The overlapped structure of the rotated substituent

\section{Interaction Energy}

The interaction energy between molecules in the dimeric systems is shown in Table 3. It can be seen that, for all the compounds considered in this study, as the interaction energy is negative, the dimeric molecules are attracting each other. For the magnitude of interaction, molecule with $\mathrm{Ph}-\mathrm{Br}$ substituent has the highest interaction energy (most negative at $-1.0573 \mathrm{eV}$ ) while $\mathrm{Ph}-2$ substituent has the lowest $(-0.5477 \mathrm{eV})$.

Between TT and CT configurations, TT has higher interaction than the CT configuration, as evidenced by the molecules with $\mathrm{Ph}$ - and $\mathrm{Ph}-\mathrm{Cl}-\mathrm{o}$ substituents. The $\mathrm{Ph}-2$ substituent, as the only polymorph in the CT configuration among the molecules with $\mathrm{Ph}$-substituent, has the smallest value of interaction energy. As for the case of Ph-Cl-o-2 and Ph-Cl-o-1, the CT configuration also has interaction energy that is of lower magnitude compared to the polymorph in TT configuration. However, no significant changes to the interaction energy can be found with or without halogen atom in the systems considered.

As for the effect of the halogens on the phenyl ring, molecules are more cohesive as the halogens in the substituents change from fluorine, chlorine, and bromine in the rank $\mathrm{F}<\mathrm{Cl}<\mathrm{Br}$. This effect is due to the polarizability of the halogens. Thus, the molecules where the substituents contain fluorine had lower attraction compared to the compound with bromine.

The interaction energies are not affected much by the different attachment sites of the halogen to the phenyl rings. This can be seen from the chlorophenyl substituent $\mathrm{Ph}-\mathrm{Cl}$, where the chlorine is either attached to para- or ortho- positions. With this substituent, the interaction
Table 3. Interaction energy of the compounds

\begin{tabular}{lcc}
\hline Substituent & Interaction Energy $(\mathrm{eV})$ & Configuration \\
\hline $\mathrm{Ph}-1$ & -0.9292 & $\mathrm{TT}$ \\
$\mathrm{Ph}-2$ & -0.5477 & $\mathrm{CT}$ \\
$\mathrm{Ph}-3$ & -0.8630 & TT \\
$\mathrm{Ph}-4$ & -0.8629 & TT \\
$\mathrm{Ph}-\mathrm{F}$ & -0.7809 & TT \\
$\mathrm{Ph}-\mathrm{Cl}-\mathrm{p}-1$ & -0.8699 & TT \\
$\mathrm{Ph}-\mathrm{Cl}-\mathrm{p}-2$ & -1.0056 & TT \\
$\mathrm{Ph}-\mathrm{Br}$ & -1.0573 & TT \\
$\mathrm{Ph}-\mathrm{Cl}-\mathrm{O}-1$ & -0.7306 & $\mathrm{CT}$ \\
$\mathrm{Ph}-\mathrm{Cl}-\mathrm{o}-2$ & -0.8806 & TT \\
\hline
\end{tabular}

energies range in between -0.731 to $-1.006 \mathrm{eV}$, where the higher value is from the attachment to the paraposition. In the para-position, the molecules are taking the head-to-tail orientation, with the molecule stack parallel to the thiourea backbone for the case of $\mathrm{Ph}-\mathrm{Cl}$ p-2 substituent. However, with higher angle of the zigzag between molecules ( $\mathrm{Ph}-\mathrm{Cl}-\mathrm{p}-1)$, the interaction between molecules becomes less. Molecules with $\mathrm{Ph}-\mathrm{Cl}-\mathrm{O}-2$ substituents have the similar head-to-tail orientation but the molecule is rotated to the substituent of the compound. This orientation has less interaction between the substituent of the molecules. While Ph-Cl-o-2 has dual $\mathrm{NH} \cdots \mathrm{S}_{\mathrm{T}}$ interaction with close substituents of the molecules, $\mathrm{Ph}-\mathrm{Cl}-\mathrm{o}-1$ have single $\mathrm{NH} \cdots \mathrm{S}_{\mathrm{T}}$ interaction with substituents that are away from each other, producing dimer with the weakest interaction energy.

\section{Non-covalent Interaction ( $\mathrm{NCl}$ )}

The noncovalent interaction is shown through the NCI isosurfaces using the RDG plot in Fig. 5. For each monomer, the dual green-red NCI isosurfaces in the region between $S_{T}$ and the phenyl ring indicate that there are attractive and repulsive interactions. In the TT configuration, the $S \cdots \pi$ interactions act as the attractive interactions (the green surfaces), while the interaction in the region of $\mathrm{S}_{\mathrm{T}}-\mathrm{C}-\mathrm{N}-\mathrm{C}_{\mathrm{P}}$ constitute the repulsive interactions (the red surface). On closer inspection, the wider the divergence between the $S_{\mathrm{T}}$ and carbon of the phenyl ring $\left(\mathrm{C}_{\mathrm{P}}\right)$ from region of $\mathrm{S}_{\mathrm{T}}-\mathrm{C}-\mathrm{N}-\mathrm{C}_{\mathrm{P}}$, the lesser red isosurface will be shown. These two interactions are typical for the molecules with TT configuration for $\mathrm{Ph}$ or 


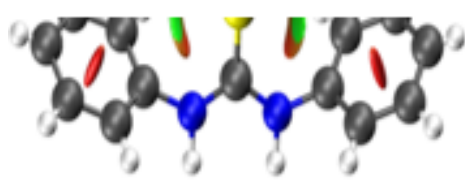

$\mathrm{Ph}-1$

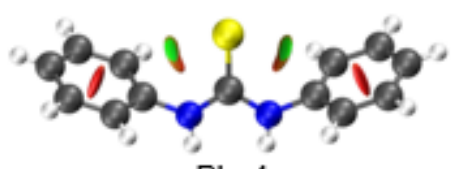

$\mathrm{Ph}-4$

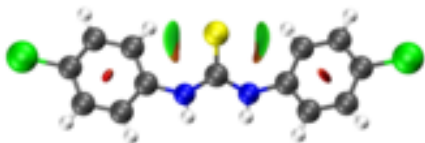

$\mathrm{Ph}-\mathrm{Cl}-\mathrm{p}-2$

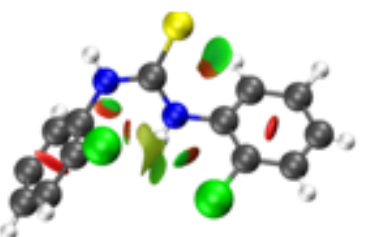

$\mathrm{Ph}-\mathrm{Cl}-0-1$ (b)

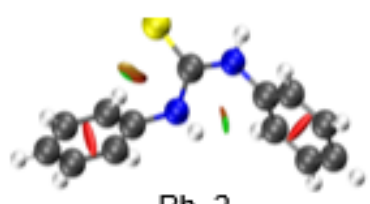

$\mathrm{Ph}-2$

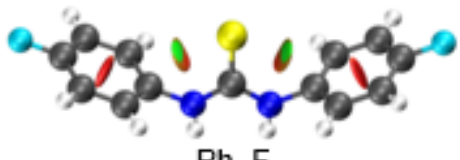

$\mathrm{Ph}-\mathrm{F}$

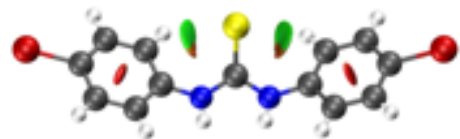

$\mathrm{Ph}-\mathrm{Br}$

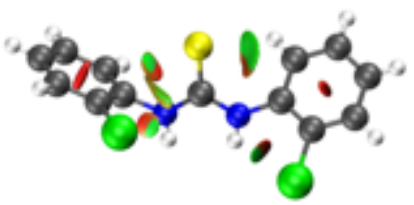

$\mathrm{Ph}-\mathrm{Cl}-0-2$
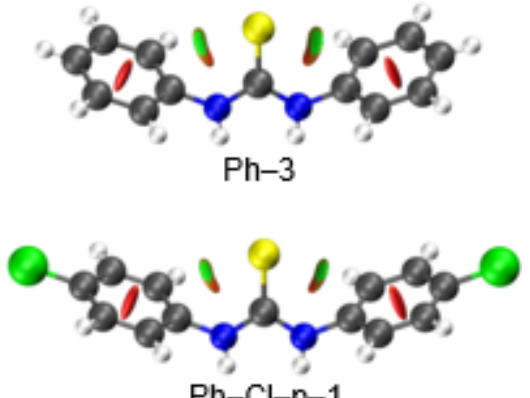

$\mathrm{Ph}-\mathrm{Cl}-\mathrm{p}-1$

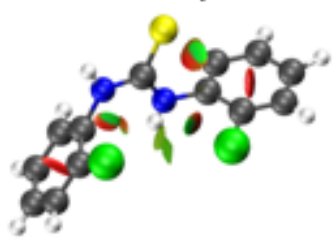

$\mathrm{Ph}-\mathrm{Cl}-0-1$ (a)

Fig 5. The NCI isosurfaces for the monomers original configuration

Ah-substituents with halogen atom attached at the paraposition. The Ph-Cl-o-2 had an extra $\mathrm{Cl} \cdots \mathrm{N}$ and $\mathrm{Cl} \cdots \mathrm{S}$ interaction from the ortho-position of the chlorine atoms.

For the molecule with the CT configuration (Ph-2 and $\mathrm{Ph}-\mathrm{Cl}-\mathrm{o}-1)$, the NCI dual green-red isosurfaces in the region between nitrogen of thiourea $\left(\mathrm{N}_{\mathrm{T}}\right)$ and the phenyl ring for the cis-orientation side comes from the $\mathrm{NH} \cdots \pi$ interaction (for attractive interaction), while the repulsive interaction is from the interaction of $\mathrm{N}_{\mathrm{T}}-\mathrm{C}-\mathrm{N}-\mathrm{C}_{\mathrm{P}}$. However, this dual color region is seen to be smaller than the one from the trans-orientation, and can be attributed from the smaller size of hydrogen as compared to the $\mathrm{S}_{\mathrm{T}}$. The interaction from the trans-orientation side of this CT configuration is the same as in the case of TT orientation. Nevertheless, in the CT configuration, for Ph-Cl-o-1, extra interaction exists in the form of $\mathrm{Cl} \cdots \mathrm{Cl}$ interaction. This can be seen from the proximity between the chlorine atoms, which is in the ortho-position of the phenyl ring, and the nitrogen of the thiourea moiety. This explains the higher interaction energy of Ph-Cl-o-1 than that of Ph-2 (as discussed in the NCI results for dimer).

For the new configurations of the molecules shown in Fig. 6 (where the substituents are rotated), the NCI isosurfaces are similar as those in the original CT and TT configurations. This indicates that the new configurations are possible as they have similar type of interactions as those that generally appear in the original configurations. CT configuration shows the combination of $\mathrm{S} \cdots \pi$ (for trans) and $\mathrm{NH} \cdots \pi$ (for cis), while TT configuration show $S \cdots \pi$ interaction for both sides. The CC configuration shows the large red isosurfaces, indicating large repulsive interaction between substituents. This explains the less preferable CC configuration compared to CT and TT configuration from the energetic aspect. The CC configuration in Fig. 6 is represented using only the molecule with $\mathrm{Ph}$ substituent, as other compounds also have similar patterns.

The non-covalent interactions of the dimer, as can be seen in Fig. 7, show that the intramolecular interaction of the dimer is similar as the monomers (Fig. 5). In between the molecules, the green NCI isosurfaces are found between $\mathrm{N}-\mathrm{H}$ and $\mathrm{S}_{\mathrm{T}}$, indicating the existence of the $\mathrm{N}-\mathrm{H} \cdot \ldots \mathrm{S}_{\mathrm{T}}$ interaction in all the compounds considered in this study. This result agrees with the findings from the experiments in which $\mathrm{NH} \cdots \mathrm{S}_{\mathrm{T}}$ interaction is important 


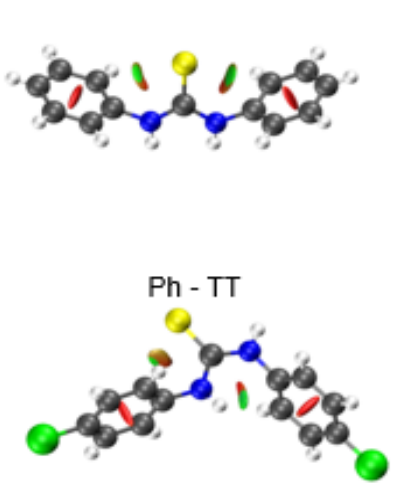

$\mathrm{Ph}-\mathrm{Cl}-\mathrm{p}-1 \mathrm{cT}$

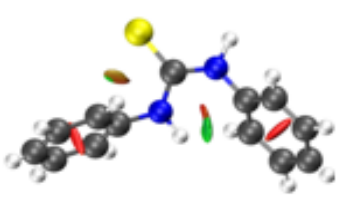

$\mathrm{Ph}-\mathrm{CT}$

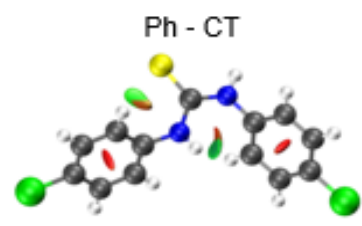

$\mathrm{Ph}-\mathrm{Cl}-\mathrm{p}-2 \mathrm{CT}$

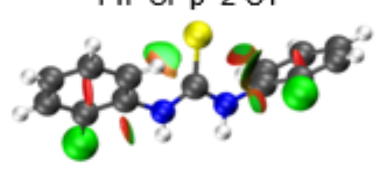

$\mathrm{Ph}-\mathrm{Cl}-0-1$ (b) TT

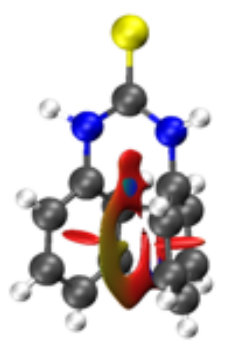

$\mathrm{Ph}-\mathrm{CC}$

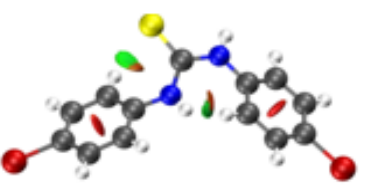

$\mathrm{Ph}-\mathrm{Br} \mathrm{CT}$

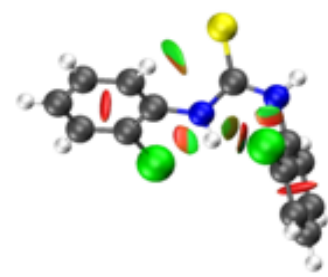

$\mathrm{Ph}-\mathrm{Cl}-0-2$ CTB

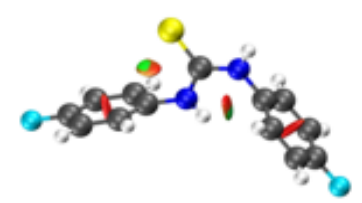

$\mathrm{Ph}-\mathrm{F}-\mathrm{CT}$

Fig 6. The NCI isosurfaces for the new configuration of the molecules
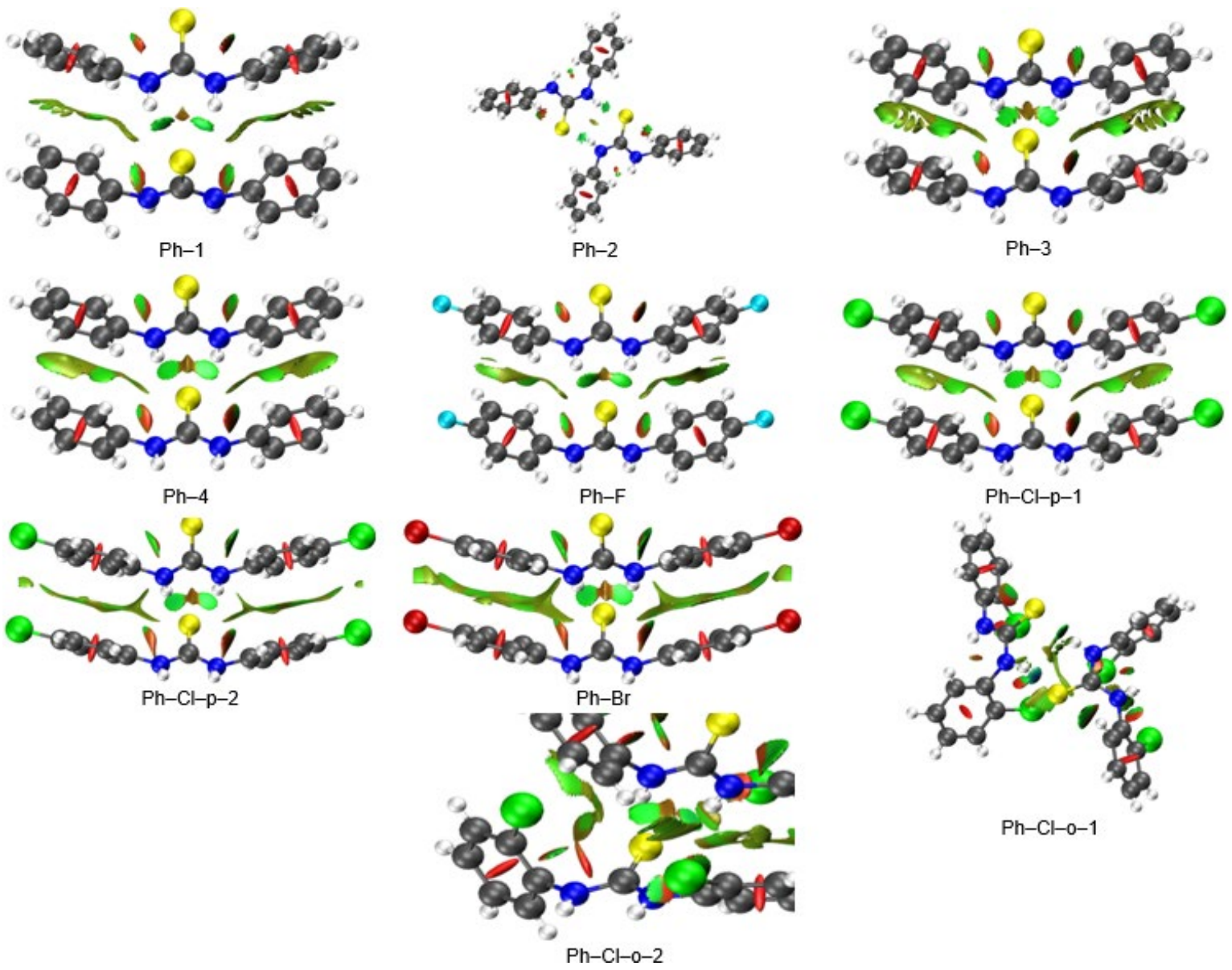

$\mathrm{Ph}-\mathrm{Cl}-0-1$

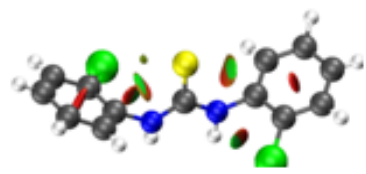

$\mathrm{Ph}-\mathrm{Cl}-0-1$ (a) TT 
in holding the molecules in the crystal structure [7-14]. Hence, not only can the $\mathrm{NH} \cdots \mathrm{S}_{\mathrm{T}}$ hydrogen bonds hold the thiourea molecules in the solid state [15], it is also responsible for the stability of the thiourea derivatives.

The higher interaction energy for dimers in the stacked TT configuration can be related to the NCI isosurfaces which show the dual $\mathrm{NH} \cdots \mathrm{S}_{\mathrm{T}}$ interaction and wide green region between substituents of the compound. For both Ph- and Ah-substituent, strength of the vdW interaction is shown to depend on the angle and distance between two molecules. Lower angle and distance will have wider $\mathrm{vdW}$ interaction resulting to higher interaction energy. For Ah-substituent, Ph-F and Ph-Clp-1 show no NCI isosurface exist between halogen atoms, while for $\mathrm{Ph}-\mathrm{Cl}-\mathrm{p}-2$ and $\mathrm{Ph}-\mathrm{Br}$, NCI isosurface appear between halogens. This agrees with the results from interaction energy fi, where Ah-substituent has higher interaction energy range compared to Ph-substituent. The amount of the vdW interaction changes according to $\mathrm{Ph}-\mathrm{F}<\mathrm{Ph}-\mathrm{Cl}<\mathrm{Ph}-\mathrm{Br}$, which is similar to the interaction energy results. $\mathrm{Ph}-\mathrm{F}$ had the lowest interaction energy due to the highest angle of $96.82^{\circ}$ between molecules.

For the CT configuration in chain arrangement, as exemplified by the $\mathrm{Ph}-2$ and $\mathrm{Ph}-\mathrm{Cl}-\mathrm{o}-1$ substituents, no enhancements of stability is observed in the dimer as the substituents are diverging from each other. However, as explained in monomer results, since $\mathrm{Ph}-\mathrm{Cl}-\mathrm{o}-1$ has extra interaction compared to $\mathrm{Ph}-2$, it reflects the higher interaction energy as shown in Table 3. The results from $\mathrm{vdW}$ isosurface agree with the observation that the molecules with $\mathrm{Ph}-\mathrm{Br}$ substituent have the strongest interaction energy, and that the dimers in the CT configuration have the lowest interaction energy compared to the TT configuration.

\section{Electrostatic Potential (ESP)}

The reactivity of the monomers and dimers are shown in Fig. 8, 9 and 10. For all the compounds considered, the $\mathrm{NH}$ bond of the thiourea moiety always show blue ESP surfaces, indicating positive potentials at the region while the red ESP surfaces at the $S_{\mathrm{T}}$ indicate the negative potentials. However, there are differences in the magnitude of the interactions between the $\mathrm{Ph}$ - and $\mathrm{Ah}$ - substituted molecules, as tabulated in Table 4. Phsubstituted molecules have lower minimum range of the red and blue surfaces compared to the Ah-substituted molecules due to the inclusion of the halogen atoms. Thus, the Ph-substituted molecules have higher ability to donate its electrons while the Ah-substituted molecules have higher ability to attract electrons.

Quantitative study of different configurations also shows differences to the potentials at the $\mathrm{NH}$ bonds of different configurations. In the CT configuration, the potentials of the blue ESPs, with energy that range from 1.50 to $1.60 \mathrm{eV}$, are smaller than those in the TT configuration which is in between 2.44 and $2.90 \mathrm{eV}$. Further differences in the electronic properties of the CT and TT configurations occurred in the ESP of the $S_{T}$. In the CT configuration ( $\mathrm{Ph}-\mathrm{Cl}-\mathrm{o}$ ), the ESP of the $\mathrm{S}_{\mathrm{T}}$ is in orange-ish color, compared to yellow-ish in the TT configuration. Numerically, the potential at the $S_{\mathrm{T}}$ for $\mathrm{Ph}-\mathrm{Cl}-\mathrm{o}$ is -1.51 and $-1.46 \mathrm{eV}$, while that in TT configurations has values between -1.47 and $-1.21 \mathrm{eV}$. Hence, while the TT configuration has enhancement in the positive potential of the $\mathrm{NH}$ sites, it also possesses slightly weaker negative potential for the $S_{\mathrm{T}}$, compared to those in the CT configuration. The green ESP surfaces at the Ah-substituted molecules indicate that these sites have average potential and that the possibility of involvement in reaction is low. Thus, the change in the structural configuration does affect the electronic properties of the compounds considered.

Fig. 9 shows the ESP surfaces for the rotated molecules. Results show that the reactive sites of all the new configurations are similar to those shown in the original configurations. The electrophilic site (blue surface) of the molecules are at the $\mathrm{NH}$ bonds region while nucleophilic site (yellow-red surface) are at the $S_{\mathrm{T}}$. Comparing ESP surfaces between the original and new configurations, energy of new configurations show unclear changes in energy pattern. However, Phsubstituent had lower minimum energy range around 1.68 to $-1.69 \mathrm{eV}$ for both TT and CT configurations compared to Ah-substituent, ranging from -1.52 to $1.20 \mathrm{eV}$. This indicates that $\mathrm{Ph}$-substituent had higher capability to act as a nucleophilic site compared to 


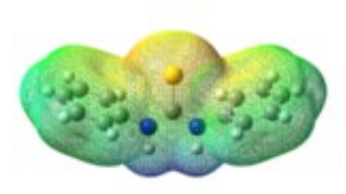

$\mathrm{Ph}-1$

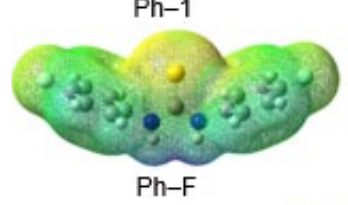

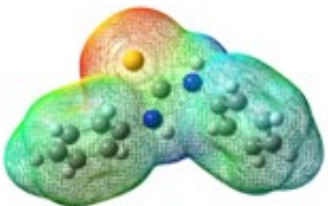

$\mathrm{Ph}-2$

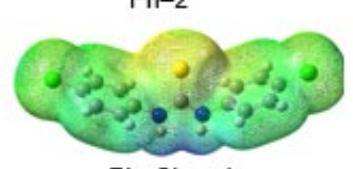

$\mathrm{Ph}-\mathrm{Cl}-\mathrm{p}-1$

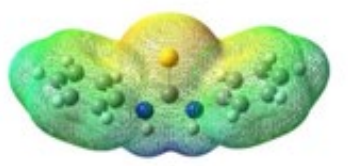

$\mathrm{Ph}-3$

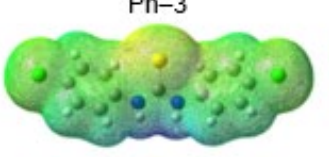

$\mathrm{Ph}-\mathrm{Cl}-\mathrm{p}-2$

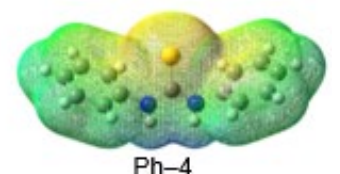

$\mathrm{Ph}-4$

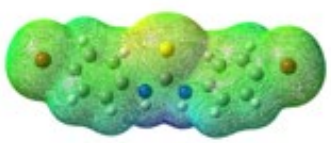

$\mathrm{Ph}-\mathrm{Br}$
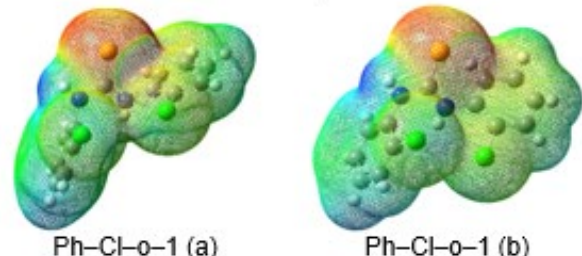

$\mathrm{Ph}-\mathrm{Cl}-0-1$ (b)

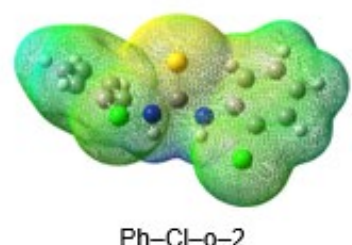

$\mathrm{Ph}-\mathrm{Cl}-0-2$

Fig 8. The ESP isosurfaces for the monomers original configuration
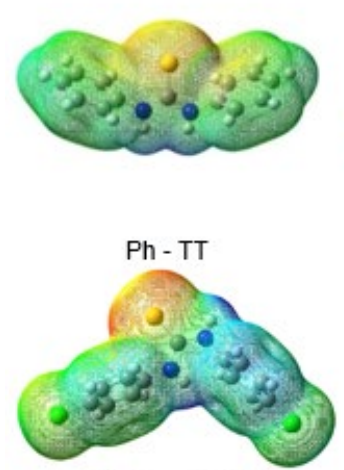

$\mathrm{Ph}-\mathrm{Cl}-\mathrm{p}-1 \mathrm{CTA}$
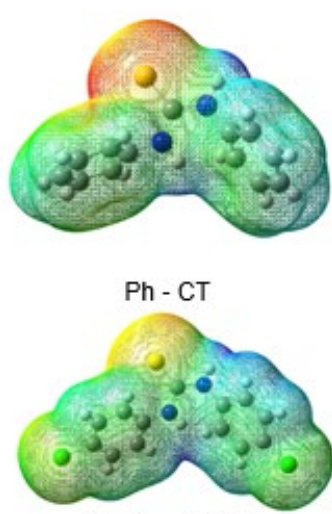

$\mathrm{Ph}-\mathrm{Cl}-\mathrm{p}-2$ CTA

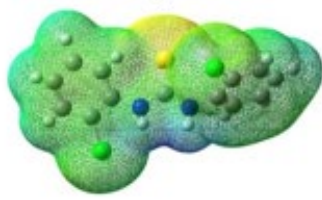

$\mathrm{Ph}-\mathrm{Cl}-0-1$ (b) TT

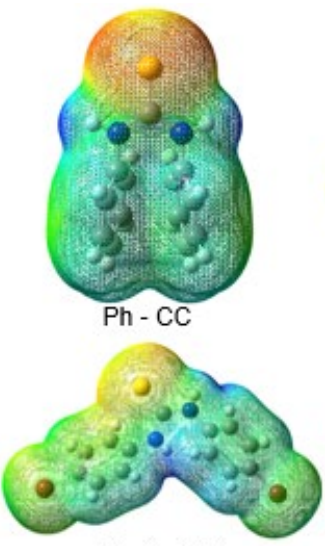

$\mathrm{Ph}-\mathrm{Br}$ CTA

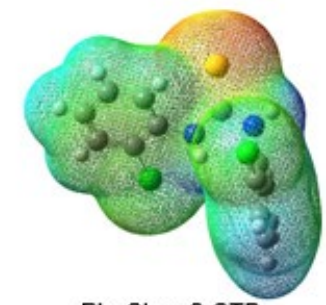

$\mathrm{Ph}-\mathrm{Cl}-0-2$ CTB

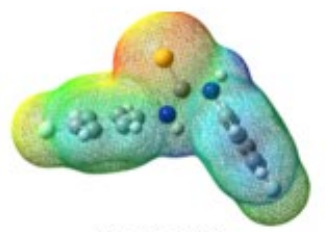

Ph-F CTA

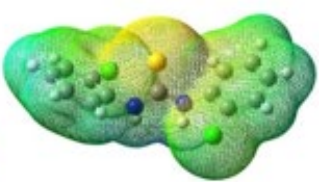

$\mathrm{Ph}-\mathrm{Cl}-0-1$ (a) TT

Fig 9. The ESP isosurfaces for the monomers new configuration

Ah-substituent. Hence, the results have similar electronic properties as the original configuration. For potential of blue ESP surfaces, rotation from TT to CT configuration shows a decrease in energy to the range of 1.55 to $1.90 \mathrm{eV}$, while rotation from CT to TT configuration increase the energy range to 2.31 to $2.41 \mathrm{eV}$. This shows that the compound of interest had higher capability to act as an electrophilic site in TT configuration. Both Ph- and Ah- substituent had similar energy range indicating that halogen did not have an effect on the potential of NH. The ESP of the interactions between the components of dimeric systems is shown in Fig. 10. Generally, the electrophilic and nucleophilic sites between the monomers are interacting with each other, where the $\mathrm{NH}$ sites attract the electron-rich $\mathrm{S}_{\mathrm{T}}$ site. The NCI isosurfaces also exist between the $\mathrm{S}_{\mathrm{T}}$ and $\mathrm{NH}$ of the two 


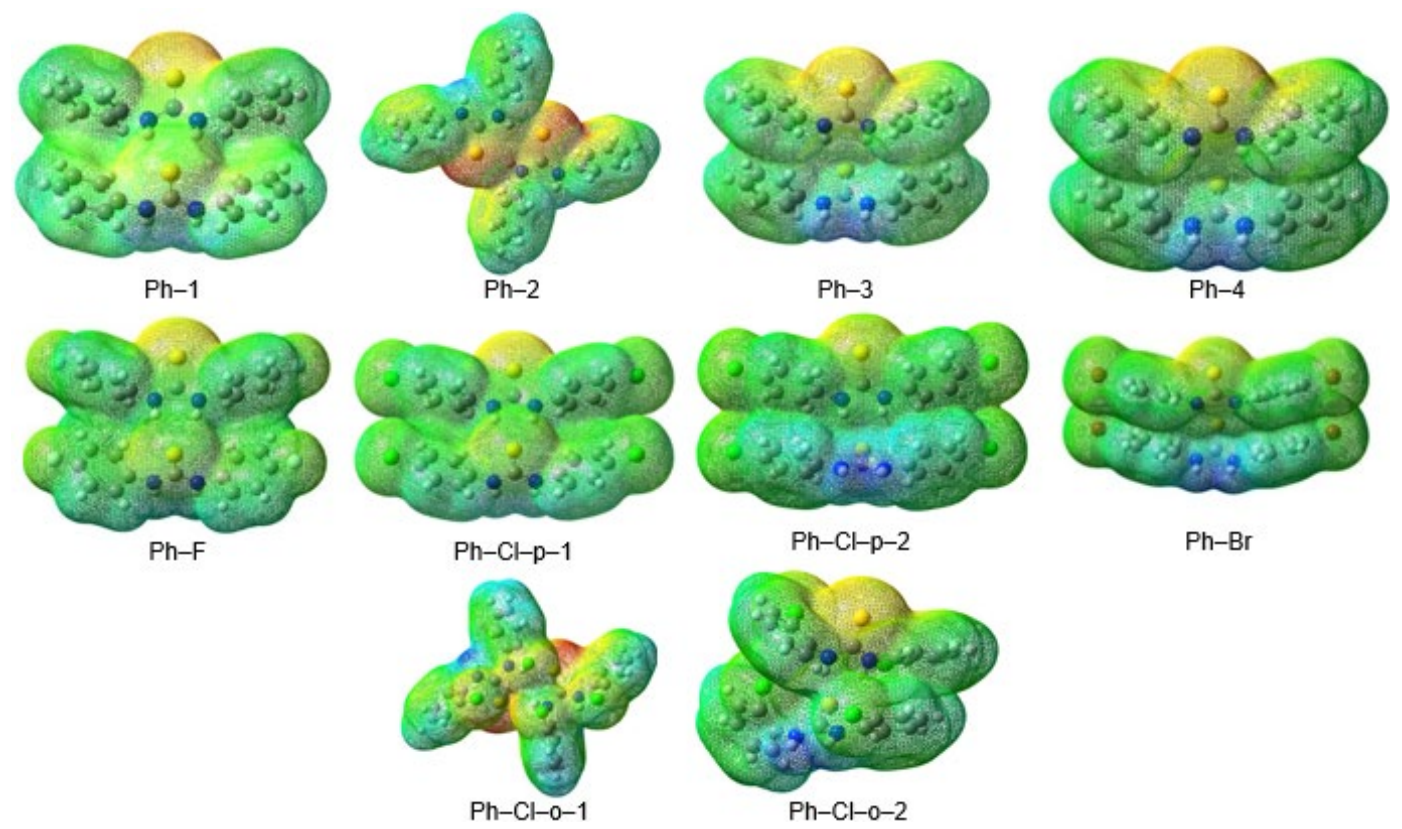

Fig 10. The ESP isosurfaces for the dimer compounds

Table 4. The ESP energy between original and rotated configurations

\begin{tabular}{lllllll}
\hline \multirow{2}{*}{ Substituent } & \multicolumn{2}{l}{ Configuration } & \multicolumn{3}{l}{ Minimum } & \multicolumn{3}{l}{ Maximum } \\
\cline { 2 - 6 } & Original & Rotated & Original conf. & Rotated conf. & Original conf. & Rotated conf. \\
\hline $\mathrm{Ph}-1$ & TT & CT & -1.6434 & -1.6846 & 2.2682 & 1.6874 \\
$\mathrm{Ph}-1$ & TT & CC & -1.6434 & -1.4233 & 2.2682 & 1.7218 \\
$\mathrm{Ph}-2$ & CT & TT & -1.6740 & -1.6899 & 1.4984 & 2.3426 \\
$\mathrm{Ph}-3$ & TT & & -1.6806 & & 2.3903 & \\
$\mathrm{Ph}-4$ & TT & & -1.6748 & & 2.3878 & \\
$\mathrm{Ph}-\mathrm{F}$ & TT & CT & -1.4653 & -1.4750 & 2.5707 & 1.6882 \\
$\mathrm{Ph}-\mathrm{Cl}-\mathrm{p}-1$ & TT & CT & -1.4748 & -1.4881 & 2.6248 & 1.6798 \\
$\mathrm{Ph}-\mathrm{Cl}-\mathrm{p}-2$ & TT & CT & -1.2288 & -1.2206 & 2.8203 & 1.8932 \\
$\mathrm{Ph}-\mathrm{Br}$ & TT & CT & -1.2073 & -1.1922 & 2.8928 & 1.8705 \\
$\mathrm{Ph}-\mathrm{Cl}-\mathrm{o}-1$ (a) & CT & TT & -1.5099 & -1.5150 & 1.6005 & 2.3104 \\
$\mathrm{Ph}-\mathrm{Cl}-\mathrm{o}-1$ (b) & CT & TT & -1.4594 & -1.4288 & 1.5653 & 2.4115 \\
$\mathrm{Ph}-\mathrm{Cl}-\mathrm{O}-2$ & TT & CT & -1.4560 & -1.4592 & 2.4424 & 1.5515 \\
\hline
\end{tabular}

monomers, indicating their importance in the interaction of molecules in crystal systems [7-14]. For the dimers, other than the sites where the monomers interact, the individual monomers also show similar reactive sites as in the case of the monomer, as shown in Fig. 9.

\section{- CONCLUSION}

In this work, we studied the conformational stability of the polymorphic diphenylthiourea and diarylhalidethiourea substituted compounds. Without changing intermolecular hydrogen bonding and geometry of the molecules, energetic study concludes that compounds are more stable in CT configuration as monomers. However, the interaction energy for the molecules in TT configuration is higher. This shows that these compounds are flexible to coexist between CT and TT configurations. From these energetic results, supported by NCI and ESP topology isosurface, molecules rotated to new configurations show similar sites of reactivity as the original configurations.

$\mathrm{Ph}$ - and Ah-substituted molecules have similar reactive sites where the sulphur of thiourea moiety acts 
as the nucleophilic site, while the $\mathrm{NH}$ of thiourea moiety acts as the electrophilic sites. However, quantitative studies of the ESP shows that the Ph-substituted molecules are better electron donors and Ah-substituted molecules are better electron acceptors.

\section{- REFERENCES}

[1] Shashidhar, Thiruvenkatam, V., Shivashankar, S.A., Halli, M.B., and Guru Row, T.N., 2006, 1,3-Bis(4methoxyphenyl)thiourea, Acta Crystallogr., Sect. E: Struct. Rep. Online, 62 (4), o1518-o1519.

[2] Bryantsev, V.S., Firman, T.K., and Hay, B.P., 2005, Conformational analysis and rotational barriers of alkyl- and phenyl-substituted urea derivatives, $J$. Phys. Chem. A, 109 (5), 832-842.

[3] Phetsuksiri, B., Jackson, M., Scherman, H., McNeil, M., Besra, G.S., Baulard, A.R., Slayden, R.A., DeBarber, A.E., Barry, C.E., Baird, M.S., Crick, D.C., and Brennan, P.J., 2003, Unique mechanism of action of the thiourea drug isoxyl on Mycobacterium tuberculosis, J. Biol. Chem., 278 (52), 53123-53130.

[4] Li, J., Bourne, S.A., de Villiers, M.M., Crider, A.M., and Caira, M.R., 2011, Polymorphism of the antitubercular isoxyl, Cryst. Growth Des., 11 (11), 4950-4957.

[5] Peña, Ú., Bernès, S., and Gutiérrez, R., 2009, (+)(S,S)-1,3-Bis[(tetrahydrofuran-2-yl)methyl]thiourea, Acta Crystallogr., Sect. E: Struct. Rep. Online, 65 (Pt 1), 096.

[6] Kotke, M., and Schreiner, P.R., 2006, Acid-free, organocatalytic acetalization, Tetrahedron, 62 (2-3), 434-439.

[7] Ramnathan, A., Sivakumar, K., Subramanian, K., Janarthanan, N., Ramadas, K., and Fun, H.K., 1995, Symmetrically substituted thiourea derivatives, Acta Crystallogr., Sect. C: Cryst. Struct. Commun., 51 (11), 2446-2450.

[8] Srivastava, P.C., Dwivedi, S., Singh, V., and Butcher, R.J., 2010, Mono- and bis(dialkyl/aryl dithio carbamato) complexes of 1,1,2,3,4,5,6-heptahydro1,1-dihalido telluranes: Synthesis, spectroscopy, structures and cleavage reaction, Polyhedron, 29 (10), 2202-2212.
[9] Štrukil, V., Igrc, M.D., Fábián, L., Eckert-Maksić, M., Childs, S.L., Reid, D.G., Duer, M.J., Halasz, I., Mottillo, C., and Friščić, T., 2012, A model for a solvent-free synthetic organic research laboratory: Click-mechanosynthesis and structural characterization of thioureas without bulk solvents, Green Chem., 14 (9), 2462-2473.

[10] Qin, Y.Q., Jian, F., and Liang, T.L., 2006, 1,3-Bis(4chlorophenyl)thiourea, Acta Crystallogr., Sect. E: Struct. Rep. Online, 62 (11), o5043-05044.

[11] Sarojini, B.K., Narayana, B., Swamy, M.T., Yathirajan, H.S., and Bolte, M., 2007, Redetermination of $N, N^{\prime}$-bis(4-chlorophenyl) thiourea at $173 \mathrm{~K}$, Acta Crystallogr., Sect. E: Struct. Rep. Online, 63 (9), o3879.

[12] Muhammed, N., Zia-ur-Rehman, Ali, S., and Meetsma, A., 2007, 1,3-Bis(4-bromophenyl)thiourea, Acta Crystallogr., Sect. E: Struct. Rep. Online, 63 (2), o632-0633.

[13] Ramnathan, A., Sivakumar, K., Subramanian, K., Janarthanan, N., Ramadas, K., and Fun, H.K., 1996, 1,3-Bis(2-chlorophenyl)thiourea, Acta Crystallogr., Sect. C: Cryst. Struct. Commun., 52 (1), 134-136.

[14] Yeo, C.I., and Tiekink, E.R.T., 2011, 1,3-Bis(2chlorophenyl)thiourea: A monoclinic polymorph, Acta Crystallogr., Sect. E: Struct. Rep. Online, 67 (11), o2965.

[15] Lenthall, J.T., Foster, J.A., Anderson, K.M., Probert, M.R., Howard, J.A.K., and Steed, J.W., 2011, Hydrogen bonding interactions with the thiocarbonyl $\pi$-system, CrystEngComm, 13 (9), 3202-3212.

[16] Tsuzuki, S., Honda, K., Uchimaru, T., Mikami, M., and Tanabe, K., 2002, Origin of attraction and directionality of the $\pi / \pi$ interaction: Model chemistry calculations of benzene dimer interaction, J. Am. Chem. Soc., 124 (1), 104-112.

[17] Frisch, M.J., Trucks, G.W., Schlegel, H.B., Scuseria, G.E., Robb, M.A., Cheeseman, J.R., Scalmani, G., Barone, V., Mennucci, B., Petersson, G.A., Nakatsuji, H., Caricato, M., Li, X., Hratchian, H.P., Izmaylov, A.F., Bloino, J., Zheng, G., Sonnenberg, 
J.L., Hada, M., Ehara, M., Toyota, K., Fukuda, R., Hasegawa, J., Ishida, M., Nakajima, T., Honda, Y., Kitao, O., Nakai, H., Vreven, T., Montgomery Jr., J.A., Peralta, J.E., Ogliaro, F., Bearpark, M., Heyd, J.J., Brothers, E., Kudin, K.N., Staroverov, V.N., Keith, T., Kobayashi, R., Normand, J., Raghavachari, K., Rendell, A., Burant, J.C., Iyengar, S.S., Tomasi, J., Cossi, M., Rega, N., Millam, J.M., Klene, M., Knox, J.E., Cross, J.B., Bakken, V., Adamo, C., Jaramillo, J., Gomperts, R., Stratmann, R.E., Yazyev, O., Austin, A.J., Cammi, R., Pomelli, C., Ochterski, J.W., Martin, R.L., Morokuma, K., Zakrzewski, V.G., Voth, G.A., Salvador, P., Dannenberg, J.J., Dapprich, S., Daniels, A.D., Farkas, O., Foresman, J.B., Ortiz, J.V., Cioslowski, J., and Fox, D.J., 2013, Gaussian 09, Revision D.01, Gaussian Inc., Wallingford CT.

[18] Castro, M., Cruz, J., Otazo-Sánchez, E., and PerezMarín, L., 2003, Theoretical study of the $\mathrm{Hg}^{2+}$ recognition by 1,3-diphenyl-thiourea, J. Phys. Chem. A, 107 (42), 9000-9007.

[19] Schäfer, A., Horn, H., and Ahlrichs, R., 1992, Fully optimized contracted Gaussian basis sets for atoms Li to Kr, J. Chem. Phys., 97 (4), 2571-2577.

[20] Peintinger, M.F., Oliveira, D.V., and Bredow, T., 2013, Consistent Gaussian basis sets of triple-zeta valence with polarization quality for solid-state calculations, J. Comput. Chem., 34 (6), 451-459.

[21] Weigend, F. and Ahlrichs, R., 2005, Balanced basis sets of split valence, triple zeta valence and quadruple zeta valence quality for $\mathrm{H}$ to $\mathrm{Rn}$ : Design and assessment of accuracy, Phys. Chem. Chem. Phys., 7 (18), 3297-3305.

[22] Grimme, S., Brandenburg, J.G., Bannwarth, C., and Hansen, A., 2015, Consistent structures and interactions by density functional theory with small atomic orbital basis sets, J. Chem. Phys., 143 (5), 054107.

[23] Kruse, H., Goerigk, L., and Grimme, S., 2012, Why the standard B3LYP/6-31G* model chemistry should not be used in DFT calculations of molecular thermochemistry: Understanding and correcting the problem, J. Org. Chem., 77 (23), 10824-10834.
[24] Grimme, S., Ehrlich, S., and Goerigk, L., 2011, Effect of the damping function in dispersion corrected density functional theory, J. Comput. Chem., 32 (7), 1456-1465.

[25] Řezáč, J., 2016, Cuby: An integrative framework for computational chemistry, J. Comput. Chem., 37 (13), 1230-1237.

[26] Řezáč, J., Riley, K.E., and Hobza, P., 2011, S66: A well-balanced database of benchmark interaction energies relevant to biomolecular structures, $J$. Chem. Theory Comput., 7 (8), 2427-2438.

[27] Kruse, H., and Grimme, S., 2012, A geometrical correction for the inter- and intra-molecular basis set superposition error in Hartree-Fock and density functional theory calculations for large systems, $J$. Chem. Phys., 136 (15), 154101.

[28] Řezáč, J., and Hobza, P., 2016, Benchmark calculations of interaction energies in noncovalent complexes and their applications, Chem. Rev., 116 (9), 5038-5071.

[29] Lu, T., and Chen, F., 2012, Multiwfn: A multifunctional wavefunction analyzer, J. Comput. Chem., 33 (5), 580-592.

[30] Humphrey, W., Dalke, A., and Schulten, K., 1996, Visual Molecular Dynamics, J. Mol. Graphics, 14, 33-38.

[31] Johnson, E.R., Keinan, S., Mori-Sánchez, P., Contreras-García, J., Cohen, A.J., and Yang, W., 2010, Revealing noncovalent interactions, J. Am. Chem. Soc., 132 (8), 6498-6506.

[32] Murray, J.S., and Politzer, P., 2009, Molecular surfaces, van der Waals radii and electrostatic potentials in relation to noncovalent interactions, Croat. Chem. Acta, 82 (1), 267-275.

[33] Dennington, R., Keith, T., and Millam, J., 2009, GaussView, Version 5, Semichem Inc., Shawnee Mission, KS.

[34] Galan, J.F., Germany, E., Pawlowski, A., Strickland, L., and Galinato, M.G., 2014, Theoretical and spectroscopic analysis of $N, N^{\prime}$-diphenylurea and $N, N$-dimethyl- $N, N^{\prime}$-diphenylurea conformations, J. Phys. Chem. A, 118 (28), 5304-5315. 